\title{
Effects of pulmonary rehabilitation in patients with mild-to-moderate chronic obstructive pulmonary disease: Bottom of an iceberg
}

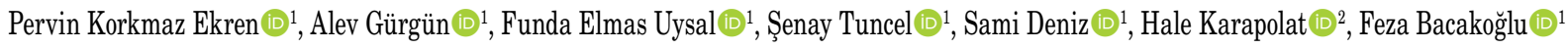 \\ ${ }^{1}$ Department of Chest Diseases, Ege University Faculty of Medicine, İzmir, Turkey \\ ${ }^{2}$ Department of Physical Therapy and Rehabilitation, Ege University Faculty of Medicine, İzmir, Turkey
}

Received: December 09, 2016 Accepted: June 21, 2017 Published online: May 23, 2018

\begin{abstract}
Objectives: This study aims to compare the effects of pulmonary rehabilitation (PR) in patients with mild-to-moderate and severe-to-very severe chronic obstructive pulmonary disease (COPD).

Patients and methods: Between January 2005 and December 2010, a total of 76 patients with mild-to-moderate (Global Initiative for Chronic Obstructive Lung Disease [GOLD] Stages I+II, n=33, mean age 66.0 \pm 8.6 years) and severe-to-very severe (GOLD Stages III+IV, n=43, mean age 63.5 \pm 8.8 years) COPD completed an eight-week outpatient PR program. Incremental and endurance shuttle walk tests (ISWT, ESWT), St. George's Respiratory Questionnaire (SGRQ), Chronic Respiratory Questionnaire (CRQ), and Hospital Anxiety and Depression Scale were assessed before and after PR. Changes after the intervention were compared between two groups.

Results: There were significant improvements in the ISWT and median $60 \mathrm{~m}$ [(-150)-(400)] in mild-to-moderate group and $70 \mathrm{~m}$ [(0)-(270)] in severe-to-very severe group (both, $\mathrm{p}<0.001)$. The ESWT time improved in both groups, 122s [(-279)-(665)] ( $\mathrm{p}=0.002)$ and $61 \mathrm{~s}[(-180)$ $(878)](\mathrm{p}<0.001)$, respectively. Significant effects were observed in all domains of the SGRQ except the impact score in mild-to-moderate patients. There were significant improvements in all domains except the symptoms score in severe-to-very severe patients. Using the CRQ, a significant improvement was shown in all domains of CRQ except the dyspnea score of mild-to-moderate patients. Anxiety and depression scores decreased after PR in both groups $(\mathrm{p}<0.05)$. According to changes in outcomes, there was no difference in any parameters between two groups.

Conclusion: This study demonstrates that patients with mild-to-moderate COPD benefit from PR comparably to patients with severe-tovery-severe COPD. Although patients with mild-to-moderate COPD are not usually symptomatic, our findings suggest that they should be included in PR.
\end{abstract}

Keywords: Anxiety; chronic obstructive pulmonary disease; depression; dyspnea; exercise; quality of life; rehabilitation.

Chronic obstructive pulmonary disease (COPD) is characterized by persistent airflow limitation and often coexists with comorbid diseases that may affect the prognosis significantly. ${ }^{[1]}$ Although lung function measurement is essential for diagnosis, there is a weak correlation between outcomes such as dyspnea, fatigue, exercise intolerance and declined lung function. ${ }^{[2,3]}$ It has been previously shown that peripheral muscle weakness contributes to exercise intolerance in COPD. ${ }^{[4]}$ The pathophysiological changes cause exercise limitation and early activity restriction in the course of the disease. Additionally, they increase the progression of the disease. ${ }^{[5]}$ Dyspnea and leg fatigue are major symptoms which limit exercise tolerance in COPD patients. These occur as a result of a complex vicious cycle which consists of impaired respiratory mechanics, gas exchange abnormalities, peripheral muscle dysfunction, limited ventilation, cardiac dysfunction and air trapping. ${ }^{[6]}$ Elbehairy et al. ${ }^{[7]}$ evaluated the underlying mechanisms of ventilatory impairment and exercise intolerance in patients with mild COPD. They showed that increased physiological dead space and wasted ventilation were the most consistent pulmonary gas exchange abnormalities during exercise in the patients with mild COPD. Despite of preserved forced expiratory volume in one

Corresponding author: Pervin Korkmaz Ekren, MD. Ege Üniversitesi Tıp Fakültesi Göğüs Hastalıkları Anabilim Dalı, 35040 Bornova, İzmir, Turkey. e-mail: pervinkorkmaz@yahoo.com 
second, these changes may result in early dynamic mechanical imbalance which causes dyspnea and exercise intolerance.

Recent evidences have demonstrated that quadriceps muscle strength and Health-Related Quality of Life (HRQOL) are impaired in patients with mild COPD. ${ }^{[8]}$ Patients at early stages of COPD may benefit from pulmonary rehabilitation (PR), and the American Thoracic Society/European Respiratory Society recommends investigation of the potential effect of PR in patients with mild to moderate COPD. ${ }^{[9]}$ The effect of exercise training in patients with mild COPD remains undetermined ${ }^{[10]}$ and further studies are necessary to assess the benefits of physical activity. ${ }^{[1]}$ Due to the limited results at early stages of COPD, in the present study, we aimed to analyze the effect of exercise training on patients with mildto-moderate COPD and to compare the results with patients having severe-to-very severe COPD.

\section{PATIENTS AND METHODS}

Between January 2005 and December 2010, a total of 76 stable patients, who were referred from the COPD outpatient clinic had Global Initiative for Chronic Obstructive Lung Disease (GOLD) criteria $^{[1]}$ and completed the PR program, were included in this retrospective study at Ege University Hospital, Chest Department. In terms of illness severity, the patients were classified as patients with mild-to-moderate (GOLD Stages I+II) and severe-to-very severe (GOLD Stages III+IV) disease. All patients were accepted to the Pulmonary Rehabilitation Unit. Exclusion criteria: (i) Patients with disabling conditions (neuromuscular diseases, malignant disorders, unstable cardiovascular diseases, orthopedic problems, severe pulmonary hypertension), (ii) Patients unwilling to complete the program, (iii) Patients with lack of motivation or with poor compliance, (iv) Patients with acute exacerbation in the previous four weeks.

This study was approved by the Ethics Committee of Ege University School of Medicine. The study was conducted in accordance with the principles of the Declaration of Helsinki. A written informed consent was obtained from each patient. All patients were ex-smokers and were receiving optimal medical treatment which included inhaling long acting anticholinergic and corticosteroid $/ \beta_{2}$-agonist according to the GOLD guideline.

The patients underwent an eight-week supervised outpatient PR program and received home exercise program once a week. The PR session consisted of education and exercise training. Exercise was started with a warm-up period followed by cycle ergometer (15 min) and treadmill training (15 min), upper and lower extremity strength training (5-10 $\mathrm{min})$ and breathing and relaxation therapies (15-20 min, each) for 60-80 $\mathrm{min} /$ day twice a week. Breathing exercises consisted of diaphragmatic, glossopharyngeal, pursed lip and segmental breathing. Relaxation exercises were performed according to the Jacobson technique of progressive muscle relaxation. ${ }^{[12]}$ Workloads for cycling and walking speed for treadmill ergometer were calculated with incremental shuttle walk test (ISWT) result $\left(\mathrm{pikVO}_{2}=4.19+[0.025 \mathrm{x}\right.$ distance of ISWT $\left.]\right) .{ }^{[13]}$ All patients were trained at 60 to $70 \%$ of peak $\mathrm{VO}_{2}$ that was calculated according to ISWT result. Exercise intensity was increased according to patient condition and exercise was applied continuously. Pulse oximetry was used during exercise, as the $\mathrm{SpO}_{2}$ had to be above $90 \%$. Resistance training was applied as one set with 8 to 12 repetitions, including the use of 8 to 10 muscles.

Dyspnea was assessed by the Medical Research Council (MRC) and Borg scales. ${ }^{[14]}$ Exercise capacity was evaluated with ISWT and endurance shuttle walk test (ESWT). ${ }^{[15,16]}$ Minimal clinically important significant differences for ISWT and ESWT were $47.5 \mathrm{~m}$ and $45-85$ second, respectively. ${ }^{[17]}$

The HRQOL was assessed by the Turkish version of St. George's Respiratory Questionnaire (SGRQ) and Chronic Respiratory Questionnaire (CRQ). The SGRO consists of three domains: symptoms, activities, and impact with scores from 0 to 100 , and the highest score represents poor quality of life (QoL). Change in score of four units for any domain is considered a clinically significant difference. ${ }^{[18,19]}$ The CRQ is constructed by dyspnea, fatigue, emotional function, and mastery dimensions. The score range of each dimension changes 1 to 7 points. The low score points to poor QoL and change of 0.5 point is accepted as clinically significant difference for this questionnaire. ${ }^{[20]}$

The Hospital Anxiety and Depression Scale (HADS) was used to assess the presence of anxiety and depressive symptoms. It has been designed to measure symptoms for depression and generalized anxiety and is self-administered easily. Anxiety (HADS-A) and depression (HADS-D) are evaluated as separate components and each consists of seven items. Higher scores indicate more severe symptomatology. A cut off score of $\geq 8$ for both scales is recommended for the evaluation. ${ }^{[21,22]}$ 


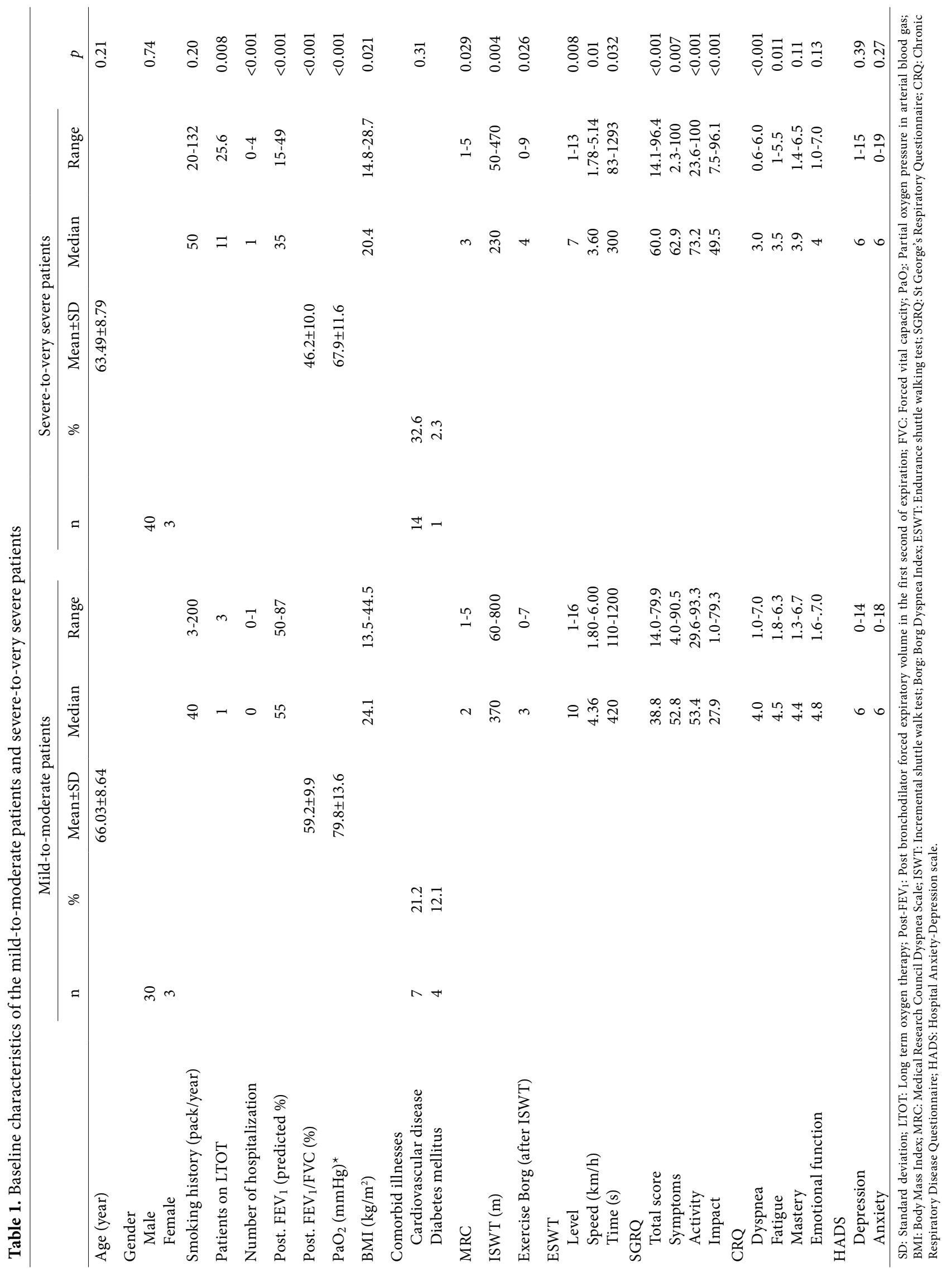




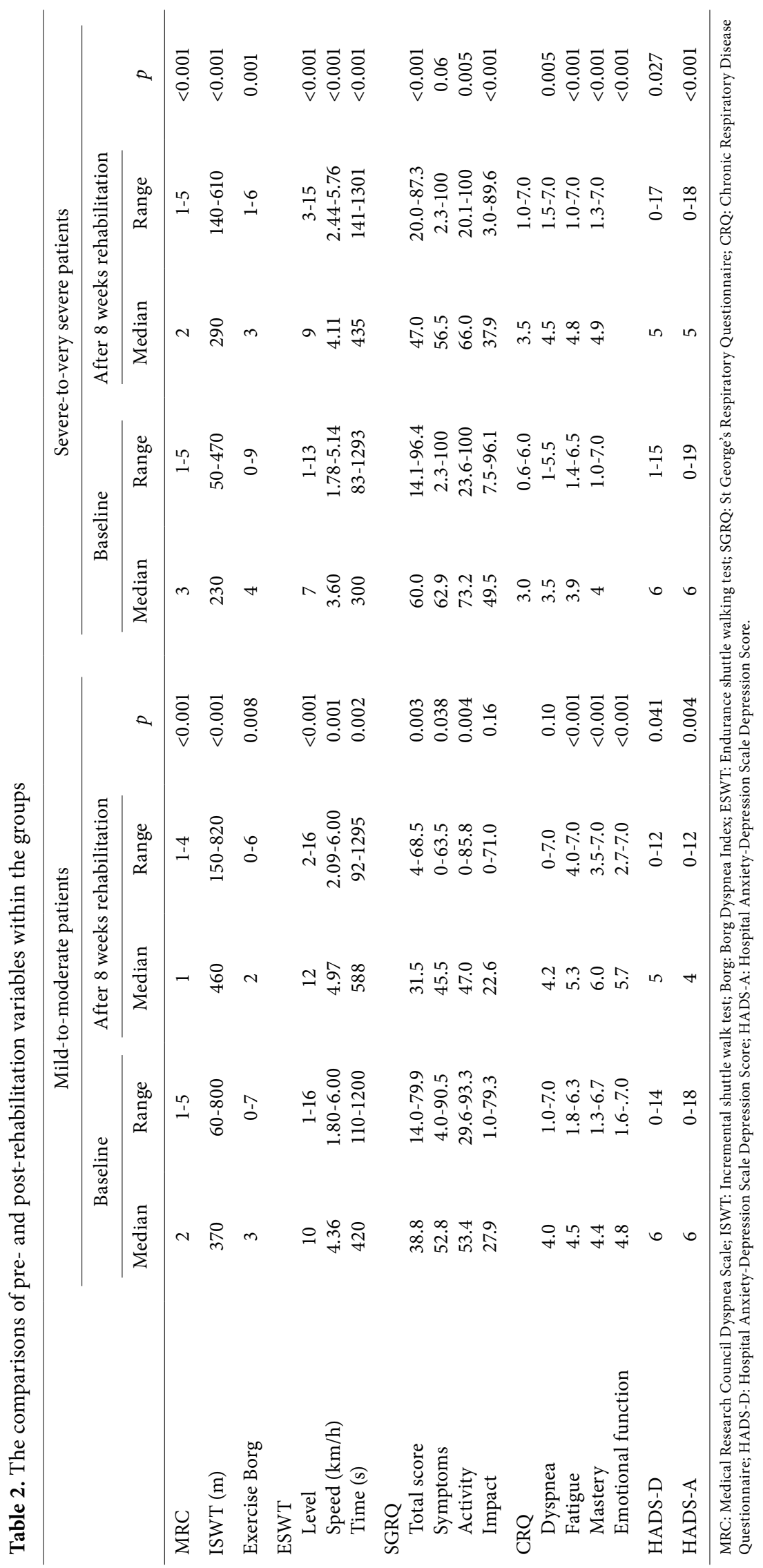


Apart from the exercise training program, the patients took part in monthly educational lectures with an interdisciplinary team on the various topics related with the disease. ${ }^{[23]}$ The patients were assessed with aforementioned variables at baseline and after the intervention. The results obtained by mild-tomoderate patients were compared with the severe-tovery severe patients. All patient data were screened from their recorded rehabilitation files before and after PR.

\section{Statistical analysis}

Data were analyzed using IBM SPSS for Windows version 20.0 (IBM Corp., Armonk, NY, USA). Descriptive statistics were performed for all recorded variables. Parametric variables between the two groups (mild-to-moderate [GOLD I+II] patients versus severe-to-very severe [GOLD III+IV] patients) were compared by the Student's t-test. The MannWhitney $U$ test was used to compare categorized or non-parametric variables between these groups. Non-parametric paired variables were analyzed with Wilcoxon test before and after PR. The results were shown as change between post-treatment and baseline levels ( $\Delta$ values). A $p$ value of 0.05 was considered statistically significant.

\section{RESULTS}

A total of 76 patients who completed the PR and had no exacerbation in four weeks before PR and during PR were enrolled in the study. Out of 76 patients, 33 were assessed as GOLD Stages I and II (mild-to-moderate) and 43 were in GOLD Stages III and IV (severe-to-very severe). The mean age was $66.0 \pm 8.6$ years and $63.5 \pm 8.8$ years, respectively. The groups were well-matched for sex, age, and smoking history at baseline. The mean Body Mass Index was 24.1 (range, $13.5-44.5$ ) $\mathrm{kg} / \mathrm{m}^{2}$ in mild-to-moderate group and 20.4 (range, 14.8-28.7) $\mathrm{kg} / \mathrm{m}^{2}$ in severe-to-very severe group, respectively. Patients in the severe-to-very severe group had worse dyspnea, higher MRC and Borg scales ( $p=0.029$, $\mathrm{p}=0.026$ ) and poorer walking distance compared with the mild-to-moderate patients $(\mathrm{p}=0.004)$ (Table 1$)$. The symptom, activity, impact and total scores of SGRQ, and the dyspnea and fatigue scores of CRQ were worse in severe-to-very severe patients than in mild-to-moderate patients at baseline $(\mathrm{p}<0.05)$. Baseline characteristics and demographic features of the patients are shown in Table 1.

Dyspnea, walking distance and endurance time, both anxiety and depression improved in mild-tomoderate and severe-to-very severe patients after the

Table 3. The comparisons of two groups for $\Delta$ median changes of variables

\begin{tabular}{|c|c|c|c|c|c|}
\hline & \multicolumn{2}{|c|}{ Mild-to-moderate patients } & \multicolumn{2}{|c|}{ Severe-to-very severe patients } & \multirow[b]{2}{*}{$p$} \\
\hline & Median & Range & Median & Range & \\
\hline$\triangle \mathrm{MRC}$ & -1.00 & $-3.00-0$ & -1 & $-3-1$ & 0.59 \\
\hline$\Delta \mathrm{ISWT}(\mathrm{m})$ & 60 & $-150-400$ & 70 & $0-270$ & 0.52 \\
\hline$\Delta$ Exercise Borg & 0 & $-5-1$ & -1 & $-6-2.5$ & 0.59 \\
\hline $\begin{array}{l}\text { ESWT } \\
\qquad \begin{array}{l}\Delta \text { Level } \\
\Delta \text { Speed }(\mathrm{km} / \mathrm{h}) \\
\Delta \text { Time }(\mathrm{s})\end{array}\end{array}$ & $\begin{array}{c}2 \\
0.49 \\
122\end{array}$ & $\begin{aligned} & -3-9 \\
-0.79 & -2.49 \\
-279 & -665\end{aligned}$ & $\begin{array}{c}2 \\
0.60 \\
61\end{array}$ & $\begin{array}{c}-3-6 \\
-0.86-1.65 \\
-180-878\end{array}$ & $\begin{array}{l}0.25 \\
0.26 \\
0.45\end{array}$ \\
\hline $\begin{array}{l}\text { SGRQ } \\
\qquad \text { Total score } \\
\Delta \text { Symptoms } \\
\Delta \text { Activity } \\
\Delta \text { Impact }\end{array}$ & $\begin{array}{l}-5.1 \\
-5.4 \\
-6.1 \\
-4.1\end{array}$ & $\begin{array}{l}-33.4-6.0 \\
-55.9-29.5 \\
-53.0-30.3 \\
-38-25.0\end{array}$ & $\begin{array}{l}-6 \\
-5.7 \\
-6 \\
-6\end{array}$ & $\begin{array}{c}-39-13.6 \\
-43.4-21.9 \\
-56-46.4 \\
-37-9.5\end{array}$ & $\begin{array}{l}0.62 \\
0.60 \\
0.79 \\
0.19\end{array}$ \\
\hline $\begin{array}{l}\text { CRQ } \\
\Delta \text { Dyspnea } \\
\Delta \text { Fatigue } \\
\Delta \text { Mastery } \\
\Delta \text { Emotional function }\end{array}$ & $\begin{array}{l}0.4 \\
0.8 \\
0.5 \\
0.8\end{array}$ & $\begin{array}{l}-2.2-3.6 \\
-1.5-4.0 \\
-0.6-3.8 \\
-0.6-4.9\end{array}$ & $\begin{array}{l}0.6 \\
0.8 \\
0.5 \\
0.7\end{array}$ & $\begin{array}{l}-2.5-5.2 \\
-1.5-3.5 \\
-1.3-2.5 \\
-0.8-3.3\end{array}$ & $\begin{array}{l}0.44 \\
0.83 \\
0.39 \\
0.69\end{array}$ \\
\hline$\Delta$ HADS-D & -1 & $-7-3$ & -1 & $-6-7$ & 0.63 \\
\hline$\triangle \mathrm{HADS}-\mathrm{A}$ & -1.5 & $-7-3$ & -2 & $-9-4$ & 0.91 \\
\hline
\end{tabular}

MRC: Medical Research Council Dyspnea Scale; ISWT: Incremental shuttle walk test; Borg: Borg Dyspnea Index; ESWT: Endurance shuttle walking test; SGRQ: St George's Respiratory Questionnaire; CRQ: Chronic Respiratory Disease Questionnaire; HADS-D: Hospital Anxiety-Depression Scale Depression Score; HADS-A: Hospital AnxietyDepression scale anxiety score. 
intervention. Exercise capacity increased after PR, with a mean score difference of $60 \mathrm{~m}$ and $70 \mathrm{~m}$ in the ISWT distance in both groups, respectively. Level, speed and endurance time increased significantly in both groups. All scores on SGRQ improved significantly from baseline to follow-up except the impact score in mild-to-moderate group and symptoms score in severe-to very severe group. Except for the dyspnea score of mild-to-moderate patients, there were also significant improvements in all domains of CRQ in both groups. Scores on dyspnea, exercise capacity, HRQOL, anxiety and depression before and after rehabilitation are shown in Table 2 . The baseline HADS-D and HADS-A scores were $6(0-14)$ and $6(0-18)$ respectively in the mild-to-moderate patients; 6 (1-15) and 6 (0-19) in severe-to-very severe patients. The patients in both groups were not diagnosed with anxiety or depression. Comparisons for all changes at outcomes in both groups are summarized in Table 3. Participation in PR program led to decrease in dyspnea and improvement in exercise capacity and QoL. We observed same outcomes also in mild-to-moderate patients after rehabilitation, as there was no difference between mild-to-moderate patients and severe-to-very severe patients in terms of improvement. These results supported the benefits of PR at early stages of the disease.

\section{DISCUSSION}

Our study demonstrated that PR was an effective treatment for improving dyspnea, exercise capacity and HRQOL in patients with mild-to-moderate and severe-to-very severe COPD. In contrast to the belief that the patients at early stages are asymptomatic, MRC was already two in patients with mild-to-moderate disease and it was three in patients with severe-to-very severe disease at baseline. Observed improvements for dyspnea, exercise capacity and life quality were similar in two groups after the rehabilitation program.

In a recent guideline, PR has been considered as a component of the management of COPD. Indeed, the rehabilitation application has become routine care for individuals with moderate to severe disease $^{8}$ and it has been concluded that mild airway obstruction has only few clinical consequences and does not require any intervention. ${ }^{[24]}$ However, according to the Burden of Obstructive Lung Disease (BOLD) study, patients with mild COPD constituted $45 \%$ of the whole COPD patient population, and the remaining patients were assigned to GOLD Stage II to IV..$^{[25]}$
There is an increasing amount of data that mild airflow obstruction is also associated with a reduction in exercise capacity in patients with COPD. ${ }^{[26]}$ Impairment in exercise capacity in mild-to-moderate disease is supported by the evidence that quadriceps muscle strength and QoL is already impaired in patients with mild COPD ${ }^{[8]}$ Even before the patients at early stages of the disease are aware of their illness, they subconsciously restrict activities and therefore patients become progressively sedentary. ${ }^{[27]} \mathrm{O}^{\prime}$ Donnell et al. ${ }^{[28]}$ found that symptomatic COPD patients with either mild or moderate airflow limitation had evidence of physiological impairment at rest and during exercise. They had more intense dyspnea and significantly lower exercise tolerance compared to healthy control group. Ofir et al. ${ }^{[3]}$ compared the symptomatic smokers who had COPD and mild airflow limitation with healthy control group. Patients with mild airflow limitation had significantly reduced exercise capacity and their exertional dyspnea rate was higher than that of healthy individuals.

The improvement in walking distance in mild-tomoderate patients was $60 \mathrm{~m}$ in our study. Considering that $47.5 \mathrm{~m}$ is the minimum clinically significant difference for ISWT in patients with COPD ${ }^{[17]}$ this may be evaluated as an increase in functional capacity which resulted from PR in mild-to-moderate patients. In Jacome's study 10, the improvement in walking distance was $32 \mathrm{~m}$ after intervention although patients in the study had only mild airflow obstruction and the PR program was three times a week. Improvement exercise tolerance was maintained at six and nine months after 12-week PR program for patients with mild COPD. ${ }^{[29]}$ Díaz et al. ${ }^{[30]}$ also evaluated the main contributors to dyspnea intensity and exercise limitation using the 6-minute walk test (6MWT) in COPD patients with mild airflow limitation, with or without activity related dyspnea. They found that inspiratory capacity (IC) decreased during exercise in dyspneic patients with mild airflow limitation and the change in IC was not only the main contributor to dyspnea intensity, but also an independent determinant of exercise capacity.

Several guidelines for COPD recommend PR for all symptomatic patients regardless of disease severity. ${ }^{[1,31]}$ These recommendations are mainly based on the evidence of improvement in dyspnea, QoL, exercise endurance and functional capacity. In our study, all HRQOL domains improved after PR in mildto-moderate patients except for the impact domain of SGRQ and dyspnea domain of CRQ. Many studies used generic instruments for measuring HRQOL 
in moderate or severe disease. ${ }^{[32,33]}$ Only few studies compared HRQOL in COPD patients with healthy controls and included early disease stages which was often undiagnosed. ${ }^{[34]}$ Wacker et al. ${ }^{[35]}$ examined time trends in HRQOL for over ten years for middle-aged persons with early COPD stages, compared to controls without airflow limitation, and analyzed the effect of COPD in the context of common COPD-related comorbidities. They concluded that, despite small changes over a 10 year time period, it was important to prevent disease progression in patients with airflow limitation. Furthermore, awareness of HRQOL impairments at early stages is of vital importance for early identification of persons at risk and starting interventions earlier is important for preventing the progression of the disease. In our study, nearly all domains of SGRQ and CRQ were improved in severe patients with the effect of PR. Additionally, both dyspnea and impact domains improved in mild-to-moderate COPD patients, but they were not statistically significantly.

The improvement of QoL for patients with mild COPD was shown in two different studies. ${ }^{[36,37]}$ These results demonstrated that health domains could be improved with PR programs. The results support the necessity for robust study designs to establish these benefits at an early stage of COPD. In addition, PR has been shown to have a beneficial effect in reducing anxiety and dyspnea, also reported to be common in mild-to-moderate patients. ${ }^{[14,38]}$ We observed similar improvements in anxiety and depression scores in both groups after intervention.

Nonetheless, our study has some limitations. The study had a small sample size, as the patients with mild-to-moderate disease were not easily convinced to participate in a PR program. Additionally, in the current study, the muscle strength or respiratory mechanics during exercise, which would have contributed some additional information about the mechanism(s) of the observed improvement, were unable to be measured.

In conclusion, there is a need to improve awareness of functional limitations and compromised QoL at early stages of COPD. Implementing PR at early stages of COPD may improve dyspnea, exercise capacity, QoL and psychological situation. Future studies are needed to address the mechanism of improvement in mild-tomoderate patients with COPD.

\section{Declaration of conflicting interests}

The authors declared no conflicts of interest with respect to the authorship and/or publication of this article.

\section{Funding}

The authors received no financial support for the research and/or authorship of this article.

\section{REFERENCES}

1. Global Initiative for Chronic Obstructive Lung Disease (GOLD). Global strategy for the diagnosis, management and prevention of COPD. [Accessed Jan 2015.] Available from: http://goldcopd.org/download/326/

2. Cooper $\mathrm{CB}$. The connection between chronic obstructive pulmonary disease symptoms and hyperinflation and its impact on exercise and function. Am J Med 2006;119:21-31.

3. Ofir D, Laveneziana P, Webb KA, Lam YM, O’Donnell DE. Mechanisms of dyspnea during cycle exercise in symptomatic patients with GOLD stage I chronic obstructive pulmonary disease. Am J Respir Crit Care Med 2008;177:622-9.

4. Miranda EF, Malaguti C, Corso SD. Peripheral muscle dysfunction in COPD: lower limbs versus upper limbs. J Bras Pneumol 2011;37:380-8.

5. Decramer M, Rennard S, Troosters T, Mapel DW, Giardino $\mathrm{N}$, Mannino D, et al. COPD as a lung disease with systemic consequences--clinical impact, mechanisms, and potential for early intervention. COPD 2008;5:235-56.

6. O'Donnell DE, Gebke KB. Activity restriction in mild COPD: a challenging clinical problem. Int J Chron Obstruct Pulmon Dis 2014;9:577-88.

7. Elbehairy AF, Ciavaglia CE, Webb KA, Guenette JA, Jensen D, Mourad SM, et al. Pulmonary Gas Exchange Abnormalities in Mild Chronic Obstructive Pulmonary Disease. Implications for Dyspnea and Exercise Intolerance. Am J Respir Crit Care Med 2015;191:1384-94.

8. Vestbo J, Hurd SS, Agustí AG, Jones PW, Vogelmeier C, Anzueto A, et al. Global strategy for the diagnosis, management, and prevention of chronic obstructive pulmonary disease: GOLD executive summary. Am J Respir Crit Care Med 2013;187:347-65.

9. Spruit MA, Singh SJ, Garvey C, ZuWallack R, Nici L, Rochester C, et al. An official American Thoracic Society/ European Respiratory Society statement: key concepts and advances in pulmonary rehabilitation. Am J Respir Crit Care Med 2013;188:13-64.

10. Jácome C, Marques A. Pulmonary rehabilitation for mild COPD: a systematic review. Respir Care 2014;59:588-94.

11. Chavannes N, Vollenberg JJ, van Schayck CP, Wouters EF. Effects of physical activity in mild to moderate COPD: a systematic review. Br J Gen Pract 2002;52:574-8.

12. Jacobson E. Progressive relaxa-tion. 2nd ed. Chicago: University of Chicago Press; 1938.

13. Singh SJ, Morgan MD, Hardman AE, Rowe C, Bardsley PA. Comparison of oxygen uptake during a conventional treadmill test and the shuttle walking test in chronic airflow limitation. Eur Respir J 1994;7:2016-20.

14. Nici L, Donner C, Wouters E, Zuwallack R, Ambrosino N, Bourbeau J, et al. American Thoracic Society/European Respiratory Society statement on pulmonary rehabilitation. Am J Respir Crit Care Med 2006;173:1390-413. 
15. Singh SJ, Morgan MD, Scott S, Walters D, Hardman AE. Development of a shuttle walking test of disability in patients with chronic airways obstruction. Thorax 1992;47:1019-24.

16. Revill SM, Morgan MD, Singh SJ, Williams J, Hardman AE. The endurance shuttle walk: a new field test for the assessment of endurance capacity in chronic obstructive pulmonary disease. Thorax 1999;54:213-22.

17. Martinez FJ, Donohue JF, Rennard SI. The future of chronic obstructive pulmonary disease treatment-difficulties of and barriers to drug development. Lancet 2011;378:1027-37.

18. Vagaggini B, Costa F, Antonelli S, De Simone C, De Cusatis G, Martino F, et al. Clinical predictors of the efficacy of a pulmonary rehabilitation programme in patients with COPD. Respir Med 2009;103:1224-30.

19. Yildiz F, Basyigit I, Yildirim E, Boyaci H, Ilgazli A. Different bronchodilator combinations have similar effects on health status in COPD. Pulm Pharmacol Ther 2006;19:101-6.

20. Guyatt GH, Berman LB, Townsend M, Pugsley SO, Chambers LW. A measure of quality of life for clinical trials in chronic lung disease. Thorax 1987;42:773-8.

21. Zigmond AS, Snaith RP. The hospital anxiety and depression scale. Acta Psychiatr Scand 1983;67:361-70.

22. Snaith RP. The hospital anxiety and depression scale. Health Qual Life Outcomes 2003;1:29.

23. da Costa CC, de Azeredo Lermen C, Colombo C, Canterle DB, Machado ML, Kessler A, et al. Effect of a Pulmonary Rehabilitation Program on the levels of anxiety and depression and on the quality of life of patients with chronic obstructive pulmonary disease. Rev Port Pneumol 2014;20:299-304.

24. Guenette JA, Jensen D, Webb KA, Ofir D, Raghavan $\mathrm{N}$, O'Donnell DE. Sex differences in exertional dyspnea in patients with mild COPD: physiological mechanisms. Respir Physiol Neurobiol 2011;177:218-27.

25. Buist AS, McBurnie MA, Vollmer WM, Gillespie S, Burney $\mathrm{P}$, Mannino $\mathrm{DM}$, et al. International variation in the prevalence of COPD (the BOLD Study): a population-based prevalence study. Lancet 2007;370:741-50.

26. ZuWallack R. How are you doing? What are you doing? Differing perspectives in the assessment of individuals with COPD. COPD 2007;4:293-7.

27. Qaseem A, Wilt TJ, Weinberger SE, Hanania NA, Criner G, van der Molen T, et al. Diagnosis and management of stable chronic obstructive pulmonary disease: a clinical practice guideline update from the American College of Physicians, American College of Chest Physicians, American Thoracic Society, and European Respiratory Society. Ann Intern Med 2011;155:179-91.
28. O'Donnell DE, Maltais F, Porszasz J, Webb KA, Albers FC, Deng $Q$, et al. The continuum of physiological impairment during treadmill walking in patients with mild-to-moderate COPD: patient characterization phase of a randomized clinical trial. PLoS One 2014;9:96574.

29. Jácome C, Marques A. Short- and Long-term Effects of Pulmonary Rehabilitation in Patients With Mild COPD: A comparison with patients with moderate to severe copd. J Cardiopulm Rehabil Prev 2016;36:445-53.

30. Díaz AA, Morales A, Díaz JC, Ramos C, Klaassen J, Saldías F, et al. CT and physiologic determinants of dyspnea and exercise capacity during the six-minute walk test in mild COPD. Respir Med 2013;107:570-9.

31. Bratås O, Espnes GA, Rannestad T, Walstad R. Pulmonary rehabilitation reduces depression and enhances healthrelated quality of life in COPD patients--especially in patients with mild or moderate disease. Chron Respir Dis 2010;7:229-37.

32. Rutten-van Mölken MP, Oostenbrink JB, Tashkin DP, Burkhart D, Monz BU. Does quality of life of COPD patients as measured by the generic EuroQol five-dimension questionnaire differentiate between COPD severity stages? Chest 2006;130:1117-28.

33. Menn P, Weber N, Holle R. Health-related quality of life in patients with severe COPD hospitalized for exacerbations - comparing EQ-5D, SF-12 and SGRQ. Health Qual Life Outcomes 2010;8:39.

34. Janson C, Marks G, Buist S, Gnatiuc L, Gislason T, McBurnie MA, et al. The impact of COPD on health status: findings from the BOLD study. Eur Respir J 2013;42:1472-83.

35. Wacker ME, Hunger M, Karrasch S, Heinrich J, Peters A, Schulz $\mathrm{H}$, et al. Health-related quality of life and chronic obstructive pulmonary disease in early stages longitudinal results from the population-based KORA cohort in a working age population. BMC Pulm Med 2014; $14: 134$

36. Liu XD, Jin HZ, Ng B, Lu G. Therapeutic effects of qigong in patients with COPD: a randomized controlled trial. Hong Kong J Occup Ther 2012;22:38-46.

37. Golmohammadi K, Jacobs P, Sin DD. Economic evaluation of a community-based pulmonary rehabilitation program for chronic obstructive pulmonary disease. Lung 2004;182:187-96.

38. Tselebis A, Bratis D, Pachi A, Moussas G, Ilias I, Harikiopoulou $\mathrm{M}$, et al. A pulmonary rehabilitation program reduces levels of anxiety and depression in COPD patients. Multidiscip Respir Med 2013;8:41. 